\title{
RELATIONSHIP BETWEEN EARLY RECURRENCE AND MICROMETASTASES IN THE LYMPH NODES OF PATIENTS WITH STAGE I NON-SMALL-CELL LUNG CANCER
}

\author{
Riichiroh Maruyama, $\mathrm{MD}^{\mathrm{a}}$ \\ Kenji Sugio, MD \\ Tetsuya Mitsudomi, $\mathrm{MD}^{\mathrm{b}}$ \\ Genkichi Saitoh, MD ${ }^{a}$ \\ Teruyoshi Ishida, $\mathrm{MD}^{\mathrm{c}}$ \\ Keizo Sugimachi, $\mathrm{MD}^{\mathrm{a}}$
}

\begin{abstract}
Objective: This retrospective study was designed to detect occult micrometastases in the lymph nodes with the use of monoclonal anti-cytokeratin reagent, which is specific for epithelial cells but not for lymphocytes or plasmacytes, as well as to assess the relationship between the presence of occult micrometastases in the lymph nodes and an early relapse in patients with stage I non-small-cell lung cancer. Methods: The paraffin-embedded sections of 973 regional lymph nodes from 44 patients with stage I non-small-cell lung cancer were studied. We used CAM-5.2 as the primary monoclonal anti-cytokeratin reagent and an indirect staining technique with the streptavidin-biotin-peroxidase complex method. Results: We identified cytokeratin-positive cells in $31(70.5 \%)$ of 44 patients and in $91(9.4 \%)$ of the 973 lymph nodes. Of these 31 patients with cytokeratin-positive cells, 19 and 12 were restaged as having $\mathrm{N} 1$ and $\mathrm{N} 2$ disease, respectively. Thirteen patients had recurrent disease at 17 sites during the follow-up. Two of these recurrences were in the mediastinal nodes and the other 15 occurred at distant organs. Twelve of the 13 patients had micrometastatic disease in the regional lymph nodes. Disease-free survival duration was significantly shorter in the patients with micrometastases in the mediastinal lymph nodes than in patients with node-negative disease $(p=0.004)$. The independence of this prognostic significance was demonstrated by a multivariate analysis. Conclusion: These findings indicate that the detection of occult micrometastases in the mediastinal lymph nodes with monoclonal antibodies to cytokeratin can thus be used to predict an early relapse in patients with stage I non-small-cell lung cancer. (J Thorac Cardiovasc Surg 1997;114:535-43)
\end{abstract}

$\mathrm{T}$ he presence of lymph node metastases is an important prognostic factor in primary lung cancer. Even in patients with stage I non-small-cell lung cancer (NSCLC) who have no demonstrable metas-

From the Department of Surgery II, Faculty of Medicine, Kyushu University, ${ }^{a}$ Department of Thoracic Surgery, Aichi Cancer Center Hospital, ${ }^{\text {b }}$ and Department of Surgery, Hiroshima Red Cross and Atomic Bomb Survival Hospital, ${ }^{\mathrm{c}}$ Fukuoka, Japan.

Supported in part by Grants-in-Aid for Scientific Research (No. 07457300 and No. 08877216) from the Ministry of Education, Science and Culture, Japan.

Received for publication Jan. 14, 1997; revisions requested March 26, 1997; revisions received April 29, 1997; accepted for publication April 30, 1997.

Address for reprints: Riichiroh Maruyama, MD, Department of Surgery II, Faculty of Medicine, Kyushu University, 3-1-1 Maidashi, Higashi-ku, Fukuoka 812-82, Japan.

Copyright (C) 1997 by Mosby-Year Book, Inc.

$0022-5223 / 97 \$ 5.00+0 \quad \mathbf{1 2} / \mathbf{1} / \mathbf{8 2 9 1 6}$ tasis to the regional lymph nodes, recurrent disease develops within the early interval after operation, and the 5-year-survivals are estimated to be about $64 \%$ to $75 \% .^{1,2}$ This suggests that the pathologic stage as determined by conventional hematoxylineosin (HE) staining may be underestimated and thus the occult metastatic stage may remain undetected. An accurate assessment of the presence and absence of tumor cells in the regional lymph nodes is therefore critical for making an accurate prognosis for patients with lung cancer. ${ }^{3-5}$

The development of sensitive immunohistochemical techniques and specific monoclonal antibodies, such as keratin, cytokeratin (CK), and BerEp4, have increased our capacity to detect small clusters of tumor cells in breast and lung cancer or even single tumor cells in the lymph nodes that appear to be negative on examination of HE-stained slides. ${ }^{6-9} \mathrm{We}$ focused our attention on the epithelial marker, CK, which might be effective for detecting micrometas- 
Table I. Characteristics of patients with stage I NSCLC and of the control subjects in this study

\begin{tabular}{|c|c|c|c|c|}
\hline & \multicolumn{2}{|c|}{ Stage I } & \multicolumn{2}{|c|}{ Control subjects } \\
\hline & $p T 1$ NOMO & pT2 NO MO & pT1 or T2 N1 MO & $p T 1$ or $T 2 \mathrm{~N} 2 \mathrm{MO}$ \\
\hline Total & 23 & 21 & 78 & 96 \\
\hline Age, median (yr) & 64 & 71 & 64 & 63 \\
\hline \multicolumn{5}{|l|}{ Sex } \\
\hline Female & 13 & 7 & 20 & 31 \\
\hline Male & 10 & 14 & 58 & 65 \\
\hline \multicolumn{5}{|l|}{ Histologic type of cancer } \\
\hline Adenocarcinoma & 19 & 10 & 43 & 58 \\
\hline Squamous cell carcinoma & 3 & 10 & 29 & 28 \\
\hline Large-cell carcinoma & 0 & 1 & 6 & 8 \\
\hline Adenosquamous carcinoma & 0 & 0 & 0 & 2 \\
\hline Mucoepidermoid carcinoma & 1 & 0 & 0 & 0 \\
\hline
\end{tabular}

tases in the lymph nodes. The family of human CKs consists of 19 different polypeptides, ${ }^{10}$ and CKs 8 and 18 were detected in the tumor cells of both adenocarcinoma and squamous cell carcinoma of the lung. ${ }^{11}$ The anti-CK reagent (CAM-5.2) used in this study was able to recognize CKs 8 and $18 .{ }^{12}$

This retrospective study was thus designed both to detect occult micrometastases in the lymph nodes by means of a monoclonal anti-CK reagent as well as to distinguish between the presence of occult micrometastases in the lymph nodes and an early relapse in patients with node-negative stage I NSCLC.

\section{Patients, methods, and follow-up}

In a series of 95 consecutive patients operated on for NSCLC at the Department of Surgery II, Faculty of Medicine, Kyushu University, between January 1991 and December 1992, we studied 44 patients with stage I disease (23: T1 N0 M0; 21: T2 N0 M0) who underwent a lobectomy combined with a formal mediastinal and hilar node dissection. The stage of the disease was based on the TNM classification of the Union Internationale Contre Cancer (UICC). ${ }^{13}$ The patients consisted of 24 men and 20 women. The median age of the patients was 66 years, with a range from 25 to 78 years. Twenty-nine patients had adenocarcinoma, 13 had squamous cell carcinoma, one had large-cell carcinoma, and one had mucoepidermoid carcinoma. The median number of lymph nodes available for examination from each patient was 23 with a range from 8 to 45 .

After the operation, the patients were reexamined every month for 1 year, once every 2 months for an additional 2 years, once every 3 months for an additional 3 years, and thereafter at 6 -month intervals. The evaluations included a physical examination and chest roentgenograms at each visit and computed tomography and a bone scan every year. The median follow-up duration of the patients was 48 months with a range from 7 to 66 months.

To compare with $\mathrm{N}$ factor restaged by $\mathrm{CK}$, we used, as a control group, patients with completely resected pathologic T1 or T2 N1 M0 $(n=78)$ and T1 or T2 N2 M0 $(n=$ 96) NSCLC determined by conventional HE staining at our department from 1975 to 1995 . The characteristics of the patients according to the $T$ factor of stage $I$ and of the control subjects are shown in Table I.

Immunostaining procedure of CK. Paraffin-embedded tissue sections $5 \mu \mathrm{m}$ thick were floated onto $0.01 \%$ lysine-coated slides. We used the primary monoclonal antibody to CKs (clone: CAM-5.2, Becton Dickinson Immunocytometry Systems, San Jose, Calif.) and an indirect staining technique and the streptavidin-biotin-peroxidase complex method. After blocking endogenous peroxidase with hydrogen peroxide, all deparaffinized sections were incubated with $0.1 \%$ type II trypsin for 20 minutes at $37^{\circ} \mathrm{C}$ to reveal the antigenic site. Possible background staining was also removed by applying normal rabbit serum, diluted 1:10, for 20 minutes at room temperature. We applied mouse CK monoclonal antibody overnight at $4^{\circ} \mathrm{C}$; then biotinylated secondary antibody and streptavidin with mouseradish peroxidase (Nichirei Corp., Tokyo, Japan) were applied for 15 and 10 minutes, respectively. Next, all slides were counterstained with methyl green. To directly compare the effectiveness of immunohistochemical analyses with the conventional HE method, we studied two additional sections consecutive to those displaying CK-positive cells. One section was stained by routine $\mathrm{HE}$ staining, and the other was immunostained with CK. The presence of CK-positive cells within the body of the lymph nodes was considered to represent metastatic tumor cells even if only one single CK-positive cell was detected.

All slides were examined by two independent observers in a double blind fashion.

Statistical analysis. Survival was calculated from the date of operation until death or the date of the last follow-up (censored). The duration of the disease-free survival was measured from the date of operation until the first evidence of recurrence from primary NSCLC or the last date of follow-up for patients who remained alive and disease free (censored); six patients who died of a cause other than primary NSCLC without any evidence of disease were censored at death. The disease-free interval and survival were analyzed according to the Kaplan-Meier method and differences in their distribution were evaluated by means of the log-rank test. ${ }^{14,15} \mathrm{~A} p$ value less than 0.05 was defined as being statistically significant. Cox 

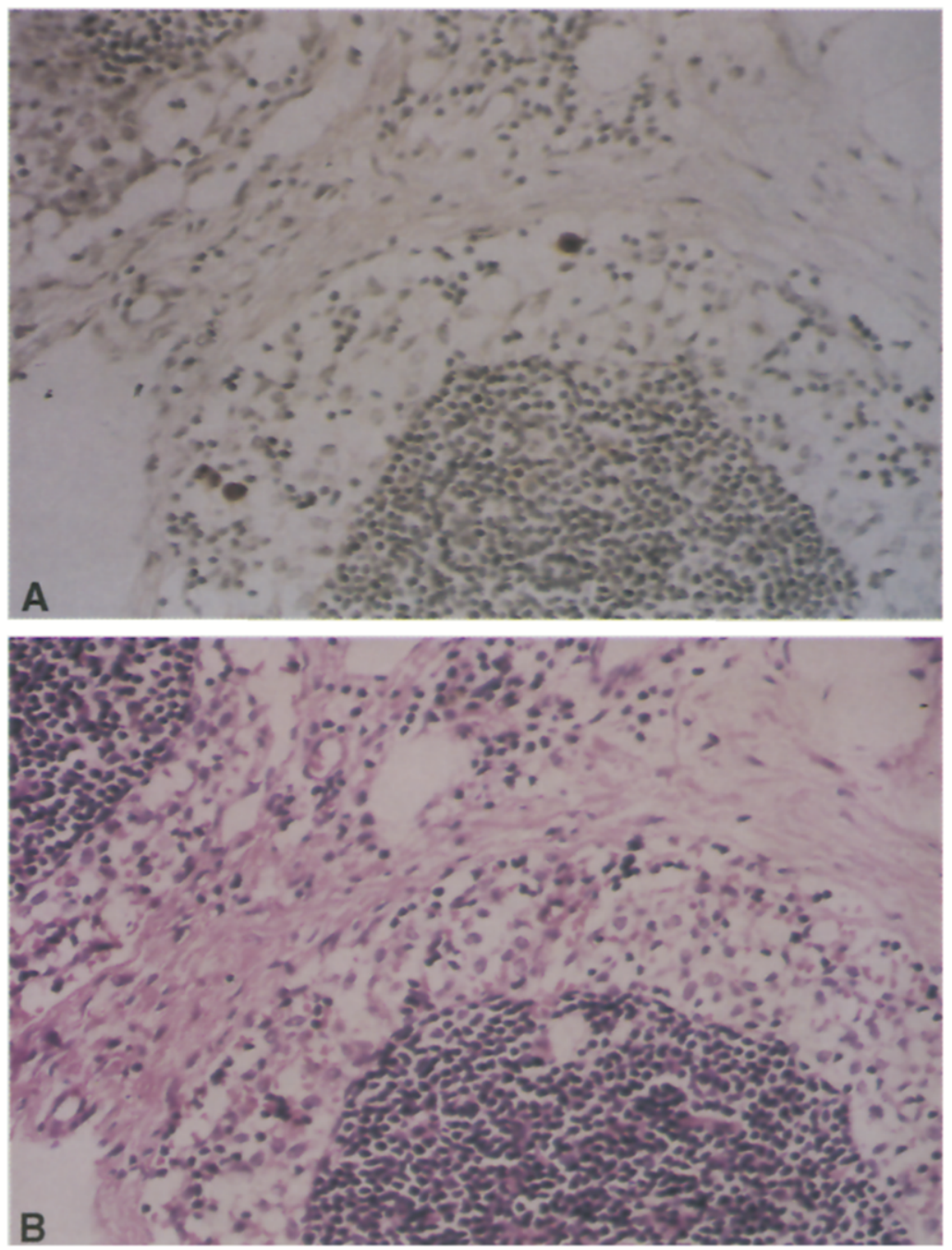

Fig. 1. A, Section of the lymph node regional to primary lung adenocarcinoma. A single CK-positive tumor cell is seen against a background of benign lymph nodes cells by means of the strept-avidin-biotin complex immunoperoxidase technique with a monoclonal $\mathrm{CK}$ antibody and methyl-green counterstaining. B, A comparable section from the same lymph nodes as depicted in $\mathbf{A}$, stained by HE. No tumor cells are visible in this routine preparation. (Original magnifications $\times 80$.)

proportional hazards models were applied for multivariate analysis. ${ }^{16}$ Data were analyzed with the use of Abacus Concepts, Survival Tools for StatView (Abacus Concepts, Inc, Berkeley, Calif.).

\section{Results}

Lymph node micrometastases detected by CK. First, we tried to confirm a reactivity of the anti-CK monoclonal antibody in the primary lesion of 44 cases in this study. All cases showed a strong positivity with CK immunohistochemistry (not shown). We examined a total of 973 lymph nodes from 44 patients with conventional stage I disease. We thus identified CK-positive cells in 25 (5.6\%) of the 450 lymph nodes from patients with T1 N0 M0 disease and in $66(12.6 \%)$ of the 523 lymph nodes from patients with $\mathrm{T} 2 \mathrm{NO} \mathrm{M} 0$ disease in whom metastases had not been detected by a routine examination of HE-stained slides. In positive lymph nodes, either single metastatic tumor cells or small clusters of such cells were usually present in the subcapsular or medullary sinuses and less frequently in the afferent lymphatics or in the true lymphoid areas of the node (Fig. 1, $A$ and $B$ ).

Among 23 patients with T1 N0 M0 disease, CKpositive cells in the lymph nodes of the hilar and 


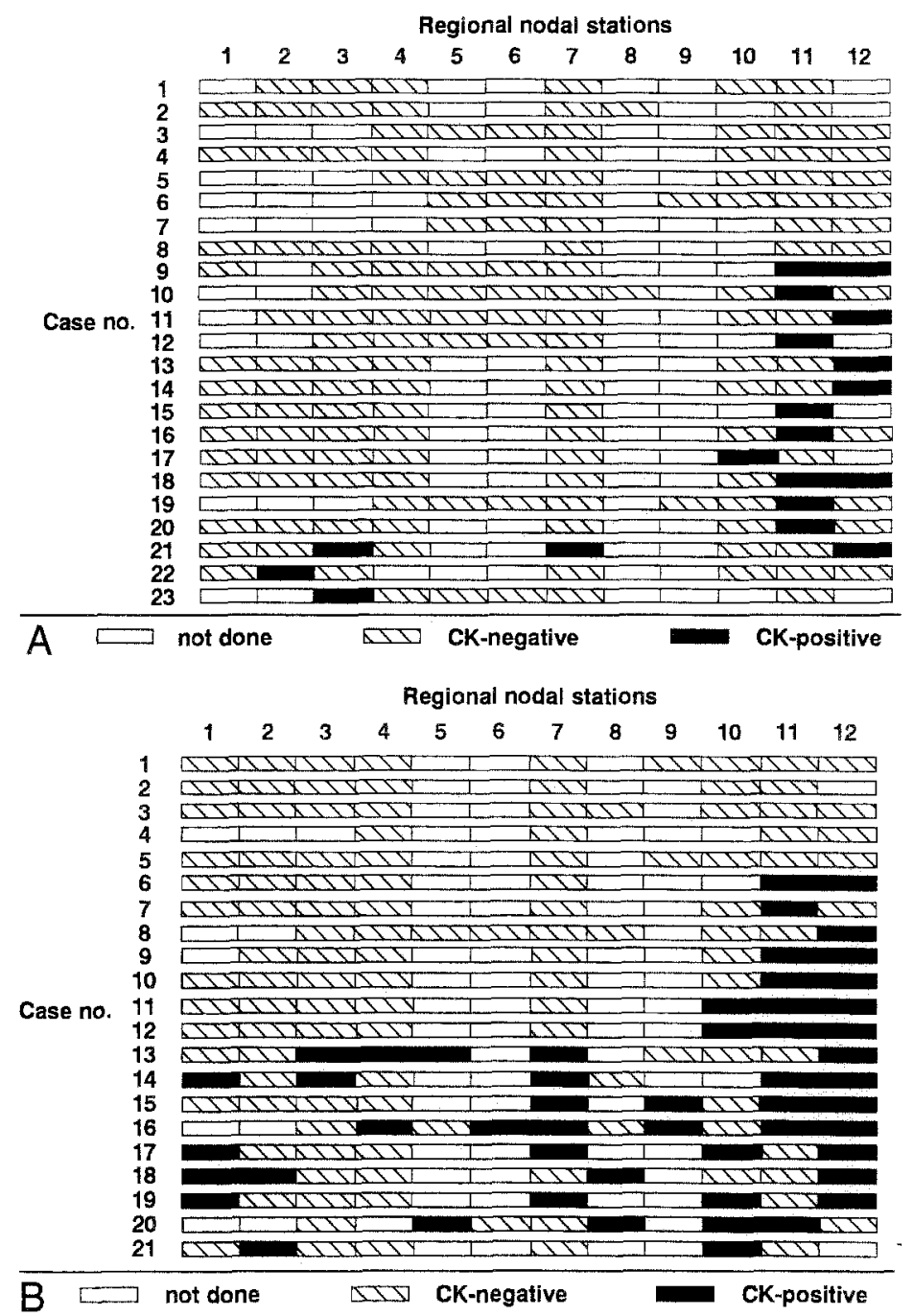

Fig. 2. A, The distribution of CK-positive tumor cells in the lymph nodes of T1 disease. B, The distribution of CK-positive tumor cells in the lymph nodes of $\mathrm{T} 2$ disease. The open squares indicate lymph nodes that were not examined, the hatched squares represent the CK-negative lymph nodes, and the closed squares denote the CK-positive lymph nodes. The numbers assigned to the regional nodal stations are as follows: number 1 indicates the highest mediastinal nodes, number 2 the paratracheal nodes, number 3 the pretracheal nodes, number 4 the tracheobronchial angle nodes, number 5 Botallo's nodes, number 6 the paraaortic (ascending aorta) nodes, number 7 the subcarinal nodes, number 8 the paraesophageal nodes, number 9 the pulmonary ligament nodes, number 10 the hilar nodes, number 11 the interlobar nodes, and number 12 the lobar nodes. ${ }^{28}$

mediastinal regions were detected in $12(52.2 \%)$ and three $(13.0 \%)$ patients, respectively. Among 21 patients with T2 N0 M0 disease, cytokeratin-positive cells in the lymph nodes of the hilar and mediastinal regions were detected in seven $(33.3 \%)$ and nine (42.9\%) patients, respectively (Fig. 2, $A$ and $B$ ).

Relationship between recurrence and micrometastasis. Follow-up data were available for at least 3 years on these patients after the operation. Among
23 patients with T1 N0 M0 disease, four patients had recurrence in this period; the sites of recurrence included the bone in one, the contralateral lung in one, the brain in one, and the mediastinal lymph nodes in one. Of the four patients with recurrence, three had N1 or N2 disease with micrometastasis in the nodes that were undetectable in the routine examination of HE staining, but were visible with the use of immunohistochemical techniques. Among 


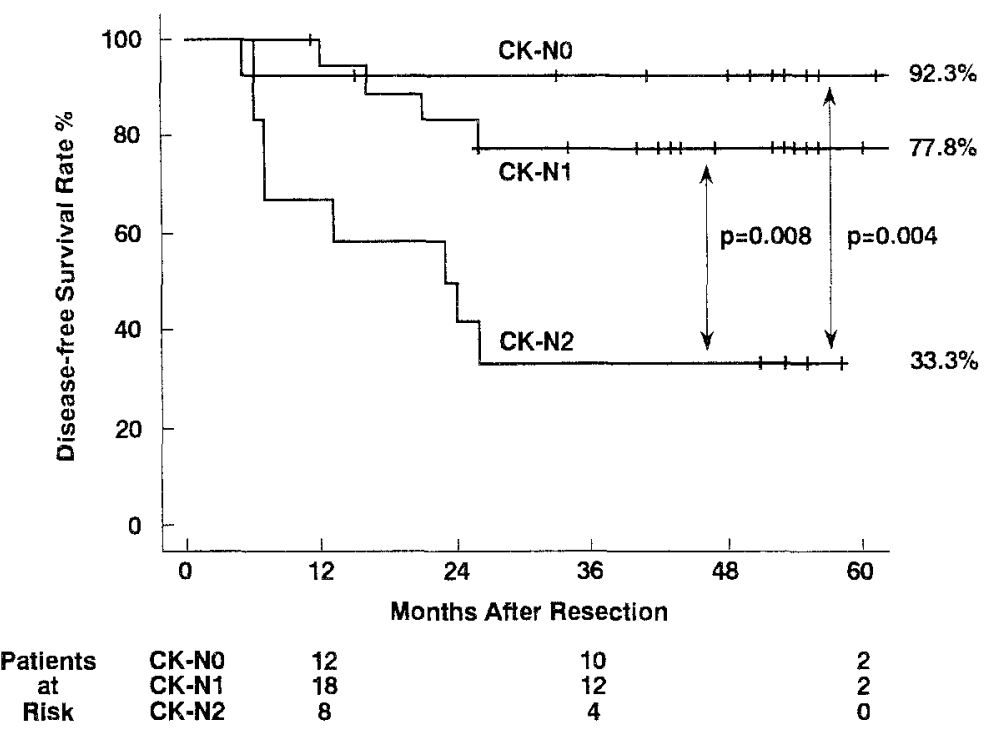

Fig. 3. The disease-free survival curves by the restaged $\mathrm{N}$ factor.

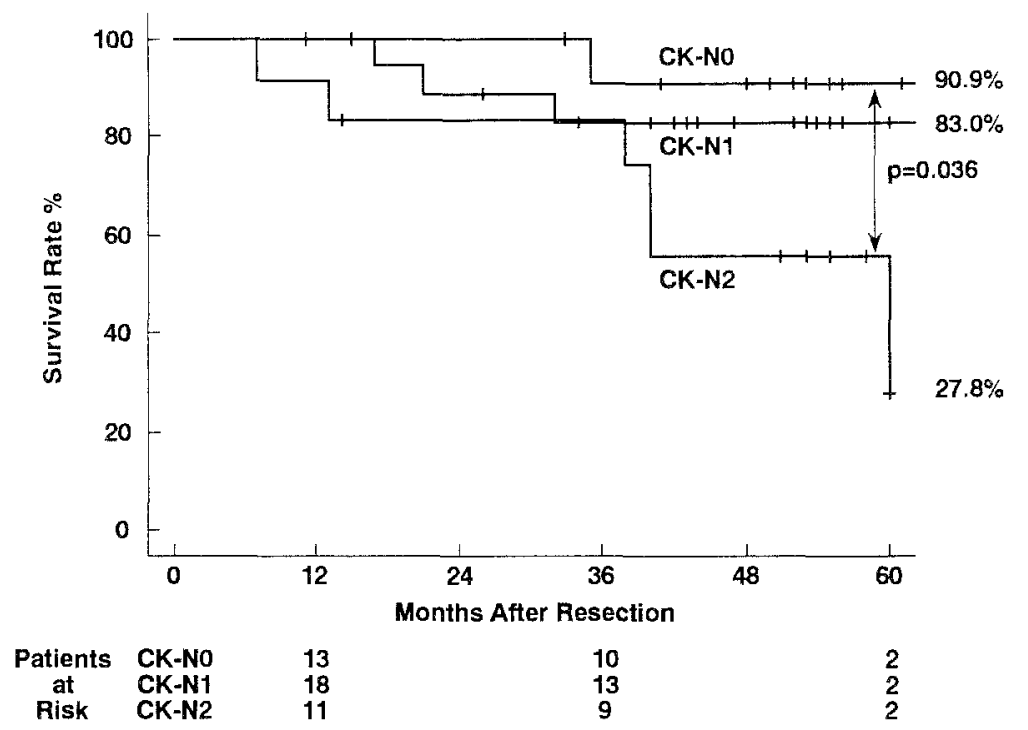

Fig. 4. The survival curves by the restaged $\mathrm{N}$ factor.

21 patients with $\mathrm{T} 2 \mathrm{~N} 0 \mathrm{M} 0$ disease, nine patients had recurrence in this period; the sites of recurrence were the mediastinal lymph nodes in one, the ipsilateral lung in two, the contralateral lung in one, the bone in three, the brain in three, the liver in two, and the skin in one. In the nine patients with recurrence, two had N1 disease and seven had N2 disease with micrometastasis in the lymph nodes.

Fig. 3 shows the disease-free survival by $\mathrm{N}$ factor restaged by CK. In patients with $\mathrm{N} 0$ disease restaged by CK (CK-NO), 3-year disease-free survival was $92.3 \%$. In patients with $\mathrm{N} 1$ disease restaged by $\mathrm{CK}$
(CK-N1), the 1- and 3-year disease-free survivals were $94.4 \%$ and $77.8 \%$, respectively. In patients with $\mathrm{N} 2$ disease restaged by CK (CK-N2), the 1 - and 3 -year disease-free survivals were $66.7 \%$ and $33.3 \%$, respectively. The duration of disease-free survival was significantly shorter in patients with CK-N2 disease than in those with CK-N0 and CK-N1 disease $(p=0.004$ and $p=0.008)$.

The overall 5 -year survival was $64.4 \%$ in this study. Fig. 4 shows the survival by $\mathrm{N}$ factor restaged by CK. The 5 -year survivals were $83.0 \%$ for patients with CK-N1 disease and $27.8 \%$ for patients with 


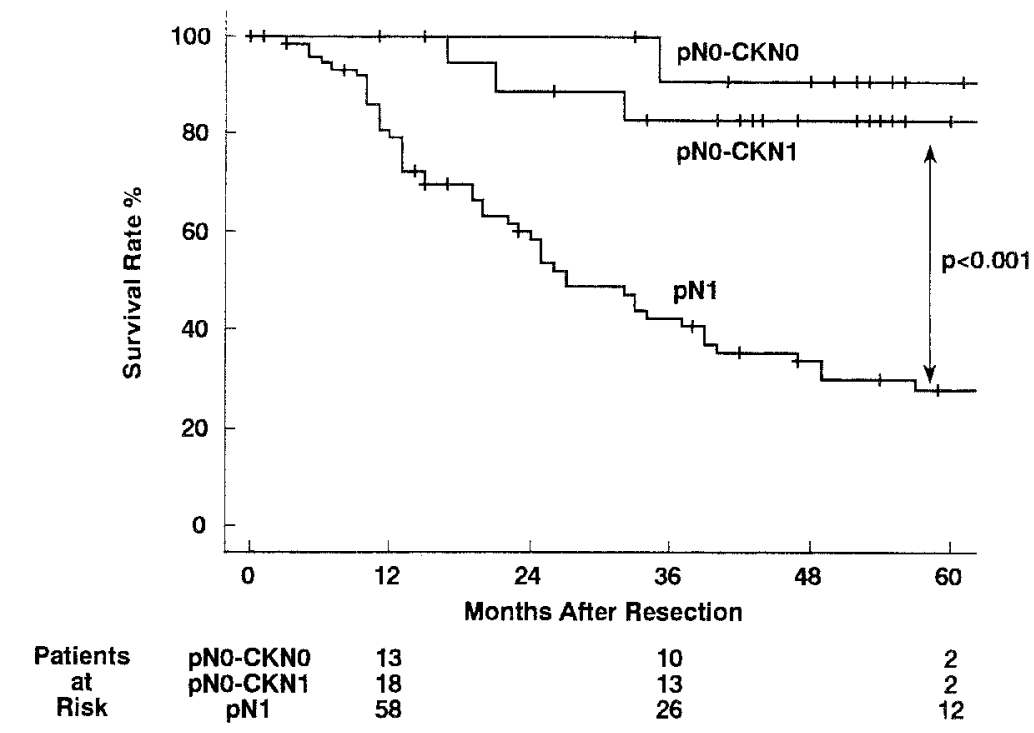

A

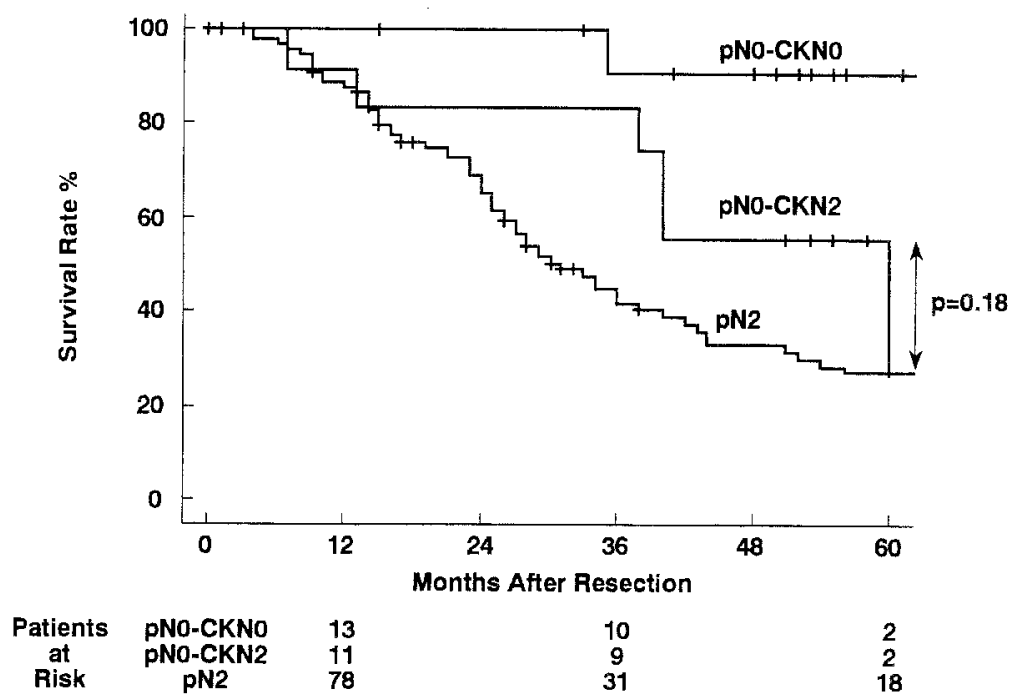

B

Fig. 5. A, The survival of patients with pathologic N1 disease and $\mathrm{N} 1$ disease restaged by $\mathrm{CK}$. B, The survival of patients with pathologic N2 disease and N2 disease restaged by CK.

CK-N2 disease. The 5-year survival was $90.9 \%$ for patients with CK-N0 disease, and the difference between CK-N0 and CK-N2 disease was significant $(p=0.036)$.

We next compared the patients having CK-N1 disease with the patients having completely resected pathologic T1 or T2 N1 M0 disease $(n=78)$, and we compared the patients having CK-N2 disease with those having completely resected pathologic $\mathrm{T} 1$ or T2 N2 M0 disease $(n=96)$. Fig. 5, $A$ shows the survival both of the patients with pathologic N1 disease and of those with CK-N1 disease. Survival was significantly shorter in the patients with pathologic N1 disease than in the patients with CK-N1 disease $(p<0.001)$. Fig. $5, B$ shows the survival of patients with pathologic N2 disease and CK-N2 disease, and the difference between the two modalities was not significant.

Table II demonstrates univariable risk ratios, 95\% confidence intervals, and $p$ values on early tumor relapse rates. It was demonstrated that only micrometastases in the mediastinal lymph nodes were 
prognostic factors in multivariable models (hazards ratio $=8.508 ; 95 \%$ confidence intervals $=1.019$, $71.039 ; p$ value $=0.048$ ).

\section{Discussion}

Up to now, the pathologic staging of cancer has been primarily based on an examination of the HE-stained nodes. Single tumor cells or small clusters of tumor cells nestled among the lymphocytes and/or sinus histiocytes can be easily overlooked, thus leading to a false-negative assessment. Occult micrometastases in the lymph nodes have also been identified by other investigators using immunohistochemical techniques in breast and lung cancer ${ }^{6-9}$ and by others using molecular biologic techniques in colorectal and lung cancer. ${ }^{17-19}$ Hayashi and associates ${ }^{18}$ reported micrometastases in the lymph nodes of the patients with colorectal cancer using the mutant allele-specific amplification method, and this method was also useful for detecting K-ras mutations. ${ }^{17}$ Betz and coworkers, ${ }^{19}$ using the reverse transcriptase-polymerase chain reaction method targeting pulmonary surfactant apoprotein, reported detecting micrometastases in the lymph nodes of patients with NSCLC.

This study emphasized the value of immunohistochemistry in detecting micrometastases in the lymph nodes and assessed the relationship between presence of micrometastases in the lymph nodes and an early relapse in patients with node-negative stage I NSCLC.

All types of epithelial tissue, both normal and malignant, contain CKs, which form the intermediate filament cytoskeleton within the epithelial cell. This family of human CKs consists of 19 different polypeptides, which have been numbered 1 through 19 by Moll and associates. ${ }^{10}$ We used CAM-5.2, which recognizes CKs 8 and 18 , as the monoclonal anti-CK reagent in this study. ${ }^{12}$ CKs 8 and 18 were detected in the tumor cells of both adenocarcinoma and squamous cell carcinoma of the lung. ${ }^{11}$ Therefore this immunohistochemical method can be effectively applied to almost all cases of NSCLC. Anti-CK reagents have some advantages and disadvantages. The anti-CK reagent is not specific for lung cancer cells, and a positive reaction was also seen with nontumor cells in the lymph nodes. In addition, Traweek, Liu, and Battifora ${ }^{20}$ reported that variable levels of keratin 8 and 18 gene expression were detected by reverse transcriptase-polymerase chain reaction targeting to $\mathrm{CK}$ in normal lymph nodes. Therefore it remains possible that the
Table II. Univariate statistics of disease-free survival

\begin{tabular}{llcc}
\hline \multicolumn{1}{c}{ Variable } & $\begin{array}{c}\text { Hazards } \\
\text { ratio }\end{array}$ & $\begin{array}{c}95 \% \\
\text { Confidence interval }\end{array}$ & $\begin{array}{c}p \\
\text { Value }\end{array}$ \\
\hline $\begin{array}{llll}\text { Sex } \\
\quad \text { Male }\end{array}$ & 1.0 & & \\
$\quad \begin{array}{l}\text { Female } \\
\text { Age (yr) } \\
\quad \text { 66 }\end{array}$ & 1.858 & $0.607,5.684$ & 0.2777 \\
$\quad \geq 66$ & 1.0 & & \\
Histologic type of cancer & 1.088 & $0.365,3.239$ & 0.8802 \\
$\quad$ Squamous & 1.0 & & \\
$\quad$ Nonsquamous & 0.849 & $0.261,2.759$ & 0.7855 \\
T factor & & & \\
$\quad$ T1 & 1.0 & & \\
$\quad$ T2 & 3.313 & $1.012,10.844$ & 0.0477 \\
N factor restaged by CK & & & \\
$\quad$ N0 & 1.0 & & \\
N1 & 2.738 & $0.306,24,504$ & 0.3678 \\
N2 & 11.701 & $1.456,94,015$ & 0.0207 \\
\hline
\end{tabular}

detection of occult metastases in lymph nodes with this molecular biologic method could be false positive. Passlick and associates ${ }^{9}$ used monoclonal antibody BerEp4, which is directed against two epithelial cell surface glycopolypeptides. ${ }^{21,22}$ The antibody does not react with mesenchymal tissue, including lymphoid tissue..$^{21}$ However, in addition to comparing the morphologic and staining similarities of primary lesions, the standard cytologic criteria of cell and nuclear size, nucleolation, and the nucleus-cytoplasmic ratio allowed us to easily distinguish CK-positive tumor cells from nontumor cells while ruling out a false-positive finding of occult metastases in the lymph nodes with this immunohistochemical method.

Even if any doubt remains as to whether a single tumor cell or small clusters of tumor cells in the lymph nodes by immunohistochemical methods reflect overt clinical metastasis, their presence might indicate a poor prognosis. According to many reports, the 5-year survivals in patients with pathologic $\mathrm{N} 1$ disease and N2 disease were $39 \%$ to $43 \%$ and $14 \%$ to $30 \%$, respectively, $2,3,23-26$ and our results correspond with these reports. We compared the patients having CK-N1 disease with the patients having completely resected pathologic $\mathrm{T} 1$ or $\mathrm{T} 2 \mathrm{~N} 1$ M0 disease, and we compared the patients having CK-N2 disease with those having completely resected pathologic T1 or T2 N2 M0 disease. As a result, tumor cells in the lymph nodes by immunohistochemical methods reflect overt pathologic metastases in the patients with CK-N2 disease, but not in those with CK-N1 disease. 
However, regarding the sites of recurrence in this study, distant metastases were more frequent than local recurrence, and the pattern of metastasis was more often hematogenous than lymphogenous. Martini and associates ${ }^{26}$ reported on 114 patients with recurrence in 214 patients with stage II lung cancer. Ninety patients (79\%) had distant metastases. As their report indicated, the nodal involvement did not necessarily reflect lymphogenous metastases, but might be an indicator of hematogenous spread. Of 31 patients with CK-detected lymph node micrometastases, 19 patients did not have a recurrence. We can be fairly certain that all patients underwent complete resections in our study. However, systemic micrometastatic spread might have occurred in some patients with CK-positive lymph nodes disease, especially CK-N2 disease. Pantel and associates $^{27}$ reported the CK immunocytologic detection of bone marrow micrometastasis in patients with NSCLC. The immunohistochemical methods with anti-CK reagent may thus be useful for performing an accurate assessment of the clinical stage.

Passlick and coworkers ${ }^{9}$ previously demonstrated that patients with lymph node micrometastases showed a significantly shorter disease-free survival duration than patients with negative nodes, and their findings were confirmed by our present study. In addition, we indicated the relationship between early recurrence and micrometastases in the mediastinal lymph nodes of patients with stage I NSCLC for the first time. We may thus believe that stage I NSCLC with CK-positive mediastinal lymph nodes represents occult advanced disease with potential indications for adjuvant therapy.

We thank Dr. Brian T. Quinn for critical comments on the manuscript.

\section{REFERENCES}

1. Naruke T, Goya T, Tsuchiya R, Suemasu K. Prognosis and survival in resected lung carcinoma based on the new international staging system. J Thorac Cardiovasc Surg 1988;96: 440-7.

2. Martini N, Bains MS, Burt ME, et al. Incidence of local recurrence and second primary tumors in resected stage I lung cancer. J Thorac Cardiovasc Surg 1995;109:120-9.

3. Naruke T, Goya T, Tuchiya R, Suemasu K. The importance of surgery to non-small cell carcinoma of lung with mediastinal lymph node metastasis. Ann Thorac Surg 1988;46:60310.

4. Bollen ECM, van Durin CJ, Theunissen PHMH, et al. Mediastinal lymph node dissection in resected lung cancer: morbidity and accuracy of staging. Ann Thorac Surg 1993; 55:961-6.

5. Funatsu T, Matsubara Y, Ikeda S, Hatakenaka R, Hanawa T,
Ishida H. Preoperative mediastinoscopic assessment of $\mathrm{N}$ factors and the need for mediastinal lymph node dissection in T1 lung cancer. J Thorac Cardiovasc Surg 1994;108:321-8.

6. Trojani M, de Mascarel I, Bonichon F, Coindre JM, Delsol G. Micrometastases to axillary lymph nodes from carcinoma of breast: detection by immunohistochemistry and prognostic significance. Br J Cancer 1987;55:303-6.

7. Chen ZL, Wen DR, Coulson WF, Giuliano AE, Cochran AJ. Occult metastases in the axillary lymph nodes of patients with breast cancer node negative by clinical and histologic examination and conventional histology. Dis Markers 1991;9:23948.

8. Chen ZL, Perez S, Holmes EC, et al. Frequency and distribution of occult micrometastases in lymph nodes of patients with non-small-cell lung carcinoma. J Natl Cancer Inst 1993; 85:493-8.

9. Passlick B, Izbicki JR, Kubuschok B, et al. Immunohistochemical assessment of individual tumor cells in lymph nodes of patients with non-small-cell lung cancer. J Clin Oncol 1994;12:1827-32.

10. Moll R, Franke WW, Schiller DL, Geiger B, Krepler R. The catalog of human cytokeratins: patterns of expression in normal epithelia. Cell 1982;31:11-24.

11. Broers JLV, Ramaekers FCS, Rot MK, et al. Cytokeratins in different types of human lung cancer as monitored by chainspecific monoclonal antibodies. Cancer Res 1988;48:3221-9.

12. Listrom MB, Dalton LW. Comparison of keratin monoclonal antibodies MAK-6, AE1:AE3, and CAM-5.2. Am J Clin Pathol 1987;88:297-301.

13. Hermanek P, Sobin LH, editors. UICC TNM classification on malignant tumours. 4 th ed, 2 nd revision. Berlin: Springer, 1992.

14. Kaplan E, Meier P. Nonparametric estimation from incomplete observation. J Am Stat Assoc 1958;53:457-81.

15. Mantel N. Evaluation of survival data and two new rank order statistics arising in its consideration. Cancer Chemo Rep 1966;50:163-70.

16. Cox DR. Regression models and life tables. J R Stat Soc 1972;34:187-220.

17. Hayashi N, Arakawa H, Nagase H, et al. Genetic diagnosis identifies occult lymph node metastases undetectable by the histopathological method. Cancer Res 1994;54:3853-6.

18. Hayashi N, Ito I, Yanagisawa A, et al. Genetic diagnosis of lymph-node metastasis in colorectal cancer. Lancet 1995;345: $1257-9$.

19. Betz C, Papadopoulos T, Buchwald J, Dämrich J, MülerHermelink HK. Surfactant protein gene expression in metastatic and micrometastatic pulmonary adenocarcinomas and other non-small cell lung carcinomas: detection by reverse transcriptase-polymerase chain reaction. Cancer Res 1995; $55: 4283-6$

20. Traweek ST, Liu J, Battifora H. Keratin gene expression in nonepithelial tissues: detection with polymerase chain reaction. Am J Pathol 1993;142:1111-8.

21. Momburg F, Moldenhauer G, Hämmerling GJ, et al. Immunohistochemical study of the expression of a Mr 34,000 human epithelium-specific surface glycoprotein in normal and malignant tissues. Cancer Res 1987;47:2883-91.

22. Latza U, Niedobitek $G$, Schwarting $R$, et al. Ber-Ep4: new monoclonal antibody which distinguishes epithelia from mesothelia. J Clin Pathol 1990;43:213-9. 
23. Mountain CF. The biological operability of stage III nonsmall cell lung cancer. Ann Thorac Surg 1985;40:60-4.

24. Martini N, Flehinger BJ. The role of surgery in N2 lung cancer. Surg Clin North Am 1987;67:1037-49.

25. Watanabe $Y$, Shimizu $J$, Oda $M$, et al. Aggressive surgical intervention in $\mathrm{N} 2$ non-small cell cancer of the lung. Ann Thorac Surg 1991;51:25361.

26. Martini N, Butt ME, Bains MS, McCormack PM, Rusch VW,
Ginsberg RJ. Survival after resection of stage II non-small cell lung cancer. Ann Thorac Surg 1992;54:460-6.

27. Pantel K, Izbicki JR, Angstwurm M, et al. Immunocytological detection of bone marrow micrometastasis in operable nonsmall cell lung cancer. Cancer Res 1993;53:1027-31.

28. Naruke T, Suemasu K, Ishikawa S. Lymph node mapping and curability at various levels of metastasis in resected lung cancer. J Thorac Cardiovasc Surg 1978;76:832-9. 